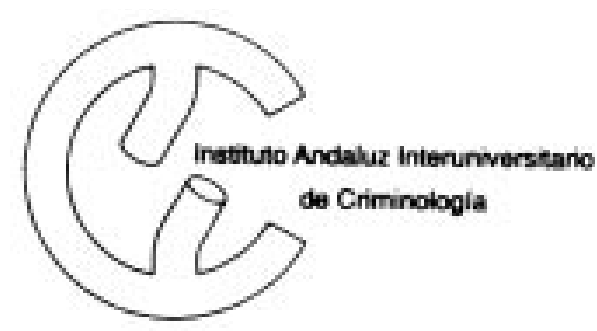

Director: Per Stangeland

Coordinadora: Ana Isabel Cerezo Domínguez Publicado por la Sección de Málaga del IAIC Facultad de Derecho, Universidad de Málaga Campus de Teatinos, 29071 MALAGA

Tel:(95) 2132325 - Fax:(95) 2132242

Depósitolegal:MA857/1996ISSN:1137-2427

El presente trabajo es fruto de la labor investigadora que está llevando a cabo el Instituto Vasco de Criminología de San Sebastián (IVAC) dentro de la línea de estudio sobre las teorías de las representaciones sociales sobre la delincuencia. Se trata de una investigación básicamente descriptiva, aunque pretendidamente también explorativa. Tiene como objetivo el conocimiento de las representaciones sociales que los jóvenes tienen sobre el delito, los factores etiológicos, los delincuentes y las instituciones creadas para resolver los conflictos-delitos. De este planteamiento se deriva su hipótesis fundamental, que mantiene que no existe una única imagen social, sino varias, determinadas por diferentes situaciones vitales.

\title{
La representación social de la delincuencia
}

\section{Visión general de la delincuencia}

La delincuencia es un fenómeno del que los jóvenes encuestados no se desentienden. Muy al contrario, les preocupa, si bien el interés que manifiestan no puede considerarse obsesivo sino que se mantiene en un término medio.

La idea que tienen sobre si la delincuencia está aumentando se acerca a lo que opinan sus mayores; como ellos, coinciden en señalar que efectivamente este fenómeno va en aumento. Aunque entre los jóvenes encuestados está algo más extendida la creencia de que la tasa de delincuencia es similar en todas las épocas, también es cierto que es insignificante la proporción de jóvenes encuestados que opinan que está decreciendo.

Sobre las posibles causas del crecimiento de la delincuencia, hay una cierta división de opiniones, que tiende a decantarse por la falta de valores humanos, más que por un incremento de la injusticia social y la marginación.
Entendemos que la delincuencia que ellos mismos califican de grave (señalan hechos tales como los asesinatos, violaciones, atracos a mano armada, grandes fraudes y estafas, graves delitos ecológicos, etc) está constituída por acciones relativamente poco frecuentes en nuestro entorno (según las Memorias de las Fiscalías en la C.A.V., el índice de asesinatos y homicidios se puede establecer en uno por cada 100.000 habitantes al año). Sin embargo, la vivencia y la percepción que tienen de los mismos es muy diferente; parecen considerarlos hechos cercanos y cotidianos.

No es difícil suponer que en esta
La presente investigación ha sido reaslizada poir el equipo investigador del Instituto vasco de Criminología, integrado por:

BERISTAIN; A.

CASTAIGNEDE, J.

DE LA CUESTA, J,L.

DENDALUZE, I.

GERMAN,I.

GONZÁLEZ,M.

HERAUT,J.C.

LARRAÑAGA,P.;

MAESO; A.,

VIDARRAZAGA;E.

visión de la realidad juega un papel importante la imagen que proyectan los medios de comunicación. Se produce una serie de procesos de selección y clasificación que deforman la realidad y,

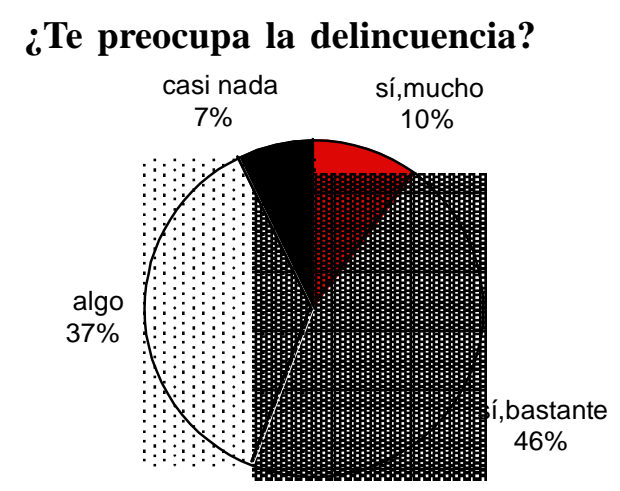

Boletín Criminológico $N^{\circ} 24 \quad$ Noviembre $1996 \quad$ Página 1




\section{Metodología}

Se ha realizado un muestreo estratificado con afijación proporcional al tamaño, estando constituidos los estratos por estudiantes de ambos sexos, procedentes de las poblaciones de San Sebastián y Bayona, y que cursan COU, $2^{\circ}$ curso de FP II y REM y sus equivalentes franceses.

Dentro de cada estrato se ha procedido al muestreo por conglomerados, entendiendo por tales las diferentes clases o aulas en las que se imparte la docencia. La unidad de muestreo ha sido las aulas, utilizándose para su elección, en San Sebastián, un proceso de sorteo aleatorio.

En San Sebastián el número de entrevistados fue de 673 alumnos pertenecientes a 25 aulas. En la ciudad de Bayona existen tres centros públicos que acogen a la gran mayoría de los, aproximadamente, 1.250 estudiantes de enseñanzas medias de la localidad. Se escogieron a 103 alumnos de 3 aulas del mayor de los centros (el 50\% del total), a 81 alumnos de 3 aulas del segundo centro, menor que el anterior, (el $40 \%$ del total) y a 23 alumnos de un aula del centro más pequeño (el 10\% del total). En conjunto se ha entrevistado a 884 jóvenes, de los cuales 673 son de San Sebastián y 211 de Bayona.

El cuestionario consta de 28 preguntas. A estas preguntas hay que añadir otro tipo de cuestiones de carácter descriptivo que han sido utilizadas como variables de cruce y que son el sexo, la edad, el tipo de estudios, la localidad y la existencia de problemas con la Justicia o la Policía. Estas dimensiones son consideradas como variables independientes a la hora de relacionarlas con las preguntas de contenido. en definitiva, la construcción de las representaciones sociales.

\section{Concepto del delito.}

Para la mayoría de los jóvenes encuestados cometer un delito es algo más que infringir la ley. Los jóvenes encuestados consideran que hay conductas socialmente inadmisibles que no tienen por qué estar recogidas en las leyes escritas. Este dato puede tener al menos, dos lecturas:

- Una progresista, en el sentido de que, en una sociedad compleja con cambios rápidos como la nuestra, la promulgación de las leyes escritas va a ir siempre por detrás de los hechos y, por lo tanto, puede haber acciones irregulares, pero legales, que los ciudadanos pueden calificar como inadmisibles.

- Otra lectura, quizás más conservadora, en el sentido de que delito es aquello que va contra la tradición o que al menos no la respeta.

De las respuestas obtenidas no se puede establecer qué idea tipo poseen los jóvenes encuestados, pero lo que queda claro es que la mayoría no se atiene a lo que simplemente dice la ley.

\section{Estereotipo de delin- cuente.}

Consideran que una persona no merece el calificativo de delincuente por cometer un sólo hecho delictivo (el primer delito). Esta idea concuerda con otra: manifiestan una cierta confianza en el autor del hecho delictivo, ya que estiman que no inexorablemente el cometer un delito lleva consigo la reincidencia, aunque para muchos las probabilidades son muy altas. En este sentido, los jóvenes encuestados parecen depositar cierta confianza en las personas: no hay que precipitarse para definir o catalogar a una persona como delincuente. Esta confianza en el ser humano se refuerza si tenemos en cuenta que los encuestados opinan que, si hubiera medios adecuados, la mayoría de los delincuentes se podrían rehabilitar.

La gran mayoría identifica la comisión de delitos con un determinado grupo, en definitiva, poseen una imagen estereotipada de los delincuentes. Se pueden observar tres conjuntos de estereotipos :

- Grupos claramente definidos

\section{¿Qué es un delito?}

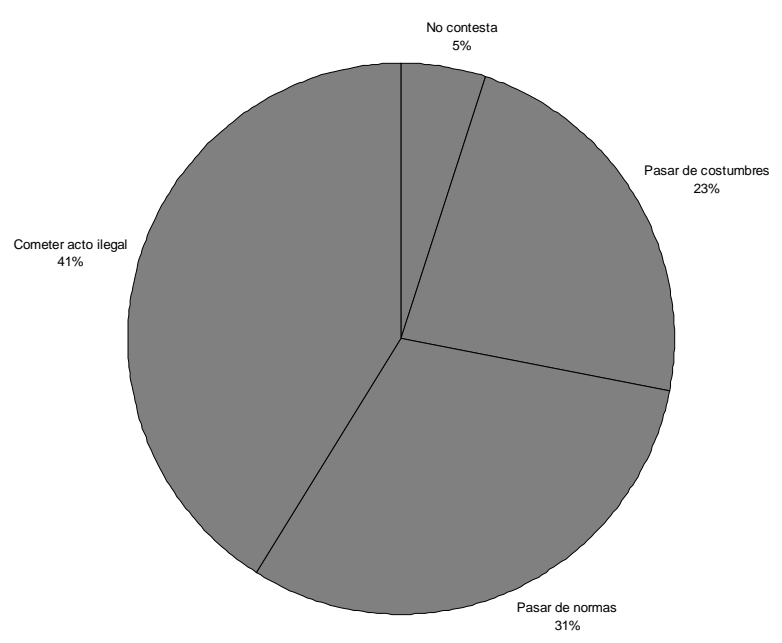

Boletín Criminológico

$N^{o} 24 \quad$ Noviembre

1996

Página 
socialmente como marginados y a los que, habitualmente, se señalacomodelincuentes:

"drogadictos", término asimilado a los dependientes de la heroína (este colectivo parece constituirse para la mayoría en el prototipo del delincuente) y "gitanos". Ambos grupos constituyen lo que socialmente se denomina como "los otros".

- Personas con poder económico y político. Son grupos lejanos para la mayoria de los jóvenes encuestados y, por lo tanto, parte integrante de ese "los otros".

- Otros grupos como "los jóvenes", "los parados" y "los inmigrantes". Posiblemente la identificación con el grupo de inmigrantes pueda ser más difícil, sin embargo, los otros dos grupos (jóvenes y parados) son mucho más cercanos y la identificación con ellos puede ser prácticamente total (jóvenes ya lo son, y muchos, o se consideran asímismos parados -»estudio porque no hay trabajo"- o saben que posiblemente constituirá una etapa en su vida).

\section{Responsabilidad del de- lincuente}

Los jóvenes encuestados consideran al delincuente como una persona consciente de sus actos $\mathrm{y}$, aunque también reconocen la importancia que puede tener su situación social desfavorecida, pocos creen que son enfermos 0 incapacitados. En lo que respecta a su responsabilidad, hay una clara división entre los que opinan que la responsabilidad se encuentra en los propios delincuentes y los que piensan que se debe al entorno en el que viven (la sociedad, los padres y la familia, por ese orden).

Los jóvenes encuestados distinguen entre lo que es consciencia y lo que es responsabilidad a la hora de cometer un hecho delictivo y, también, entre las cau-
¿Se habilitan los delincuentes?

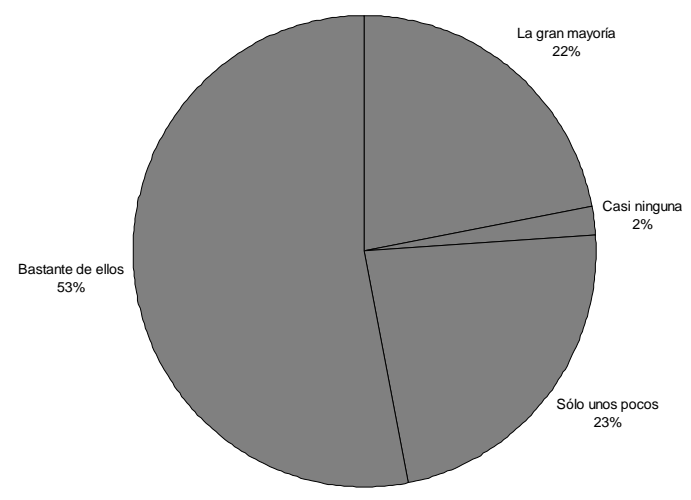

sas que originan el hecho, manifestando una tendencia a considerar a los delincuentes como individuos conscientes de lo que hacen, aludiendo a que su responsabilidad depende tanto del propio autor como de sus circunstancias de vida.

Los argumentos que utilizan los jóvenes encuestados para explicar la delincuencia son fundamentalmente de carácter externo al individuo (condiciones sociales marginales, injusticia, falta de normas en la sociedad y problemas familiares). La existencia de una experiencia familiar dura parece ser la explicación, para muchos

de los jóvenes encuestados, del comportamiento delictivo.

Un segundo tipo de razones aducidas, en cuanto a la elevada tasa de delincuentes, es de tipo individual y voluntario. Algunos consideran que los delincuentes son personas malas y viciosas de nacimiento, vagas y egoístas. Las razones individuales tienen mucha menor importancia que las sociales y, dentro de las individuales, es minoritario el grupo que utiliza como argumento para explicar la delincuencia la enfermedad. La explicación utilizada con más frecuencia es la relativa al carácter social.

\section{Responsabilidad del delicuente}

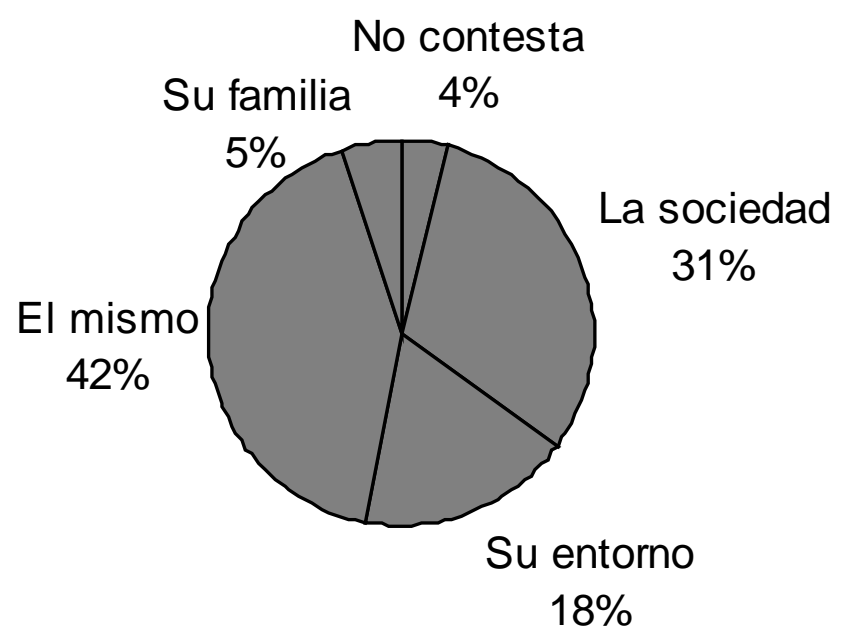

\section{Boletín Criminológico \\ $N^{o} 24 \quad$ Noviembre \\ 1996 \\ Página


LA GRAVEDAD DE CONDUCTAS ILICITAS -

Herir a alguien en defensa própia

Borracheras en público

Alborotos callejeros de noche,sin destrozos, solo ruido

Intento de suicidio

Fumar en lugares prohibidos

No pagar el los transportes públicos

Comprar bienes robados

Pintadas en edificios públicos

Peleas callejeras

Daños a jardines,papeleras y bancos

Robos en tiendas o grandes almacenes, aprovechando un descuido de los dependientes

Engañar a los clientes o a patrones por bajo rendimiento en trabajo3,5

Engañar a la compañia de seguros en un parte de accidente

Prostitución

Vender alcohol a menores

Robar la radio de un coche

Consumo de drogas ilegales

Tirón de bolso

No dar parte de un accidente de automóvil

Robar un vehículo para usarlo y luego abandonarlo

Robo de objetos en la vivienda

Mensajes publicitarios equívocos para provocar compras con

engaños

Robo de coche

Fraudes y estafas sin violencia

Delitos fiscales

Conducir un vehículo de forma peligrosa

Atentado con bomba con daños materiales pero no personales

No prestar auxilio a personas accidentadas o en peligro

Tráfico de heroína en la calle a pequeña escala, con papelinas

Acoso sexual en el trabajo

Delitos económicos, con enriquencimiento rápido

Arrojar residuos industriales o contaminantes en ríos y/o costas

Atraco a mano armada

Grandes estafas con muchos perjudicados

Atentado en que muere una persona

Tortura

Atraco a mano armada en tu vivienda, con heridas

o lesiones graves

Tráfico de drogas organizado en gran escala

Violación

Robo o atraco con asesinato

\section{La calificación de hechos ilicitos}

Entre los hechos mayoritariamente considerados por los encuestados como no sancionables se encuentran acciones tales como herir a alguien en defensa propia, borracheras en público e intento de suicidio. En el caso de la borrachera pública, parece que es un comportamiento que se repite con cierta frecuencia y que, por lo tanto, es una realidad cercana. Es curioso comprobar cómo catalogan de forma diferente el consumo de alcohol y el de estupefacientes, de tal modo que el consumo de estos últimos se considera de mayor gravedad. nan que las cárceles son duras. Además a la cárcel no le atribuyen, tal como está configurada en la actualidad, una capacidad rehabilitadora, aunque podría tenerla si se le dota de los medios oportunos.

Por otra parte, al sistema actual de aplicación de penas no le designan una capacidad rehabilitadora, sino simplemente de castigo, función que no consideran que debe de ser la principal, sino que debe de ser precisamente la rehabilitadora. Esta idea es especialmente importante en personas que, como ellos, manifiestan confianza en el ser humano y en su capacidad de reinserción, si cuentan con el apoyo necesario.

Los jóvenes encuestados opinan que hay que buscar otras medidas alternativas a la prisión que sean más eficaces. De las opiniones expresadas, se deduce que la prisión puede ser una medida que posiblemente está en función del tipo de delito, de las características del delincuente o del grado de reincidencia. Es de destacar que no son partidarios de la cárcel para aquellas personas que están en espera de juicio.

Si observamos la opinión que tienen sobre las medidas más adecuadas, se aprecia que apenas valoran como medidas más eficaces la aplicación de leyes más duras, la mejora de la cárcel y mucho menos el incremento de la presencia de la policía. Estiman que es algo más útil la reforma del sistema judicial, aunque las medidas mejor acogidas han sido aquéllas que se dirigen a una mejora de las condiciones sociales, sobre todo, de carácter material $y$, en menor medida, todo aquello que suponga un reconocimiento de valores más humanos. En cierto modo, la respuesta a esta pregunta cierra el círculo de lo que vienen diciendo con respecto a las causas: si las causas son sociales habrá que buscar soluciones sociales (preventivas) y no tanto respuestas represivas.
Boletín
Criminológico $N^{2} 24$ Noviembre 